\title{
Re-viewing 1930s Photography: A Review Essay
}

\author{
JOHN RAEBURN
}

Mind's Eye, Mind's Truth: FSA Photography Reconsidered, by James Curtis. Philadelphia: Temple University Press, 1989. x, 139 pp. Illustrations, notes, index. $\$ 29.95$ cloth.

Back Home Again: Indiana in the Farm Security Administration Photographs, 1935-1943, edited by Robert L. Reid. Bloomington: Indiana University Press, 1987. xii, 144 pp. Illustrations, bibliography. $\$ 28.95$ cloth, \$18.95 paper.

Chicago and Downstate: Illinois as Seen by the Farm Security Administration Photographers, 1936-1943, edited by Robert L. Reid and Larry A. Viskochil. Chicago and Urbana: Chicago Historical Society and University of Illinois Press, 1989. xvii, 195 pp. Illustrations, notes, bibliography, index. \$29.95 cloth, \$19.95 paper.

Picturing Minnesota, 1936-1943: Photographs from the Farm Security Administration, edited by Robert L. Reid. St. Paul: Minnesota Historical Society Press, 1989. viii, 200 pp. Illustrations, notes. $\$ 35.95$ cloth, $\$ 19.95$ paper.

AN IRONY of twentieth-century photographic history is that one of its leading figures was not a photographer. He was Roy Stryker, who directed the Farm Security Administration (FSA) photographic project from its inception in 1935 until its demise in 1943. During those eight years of economic depression and war nearly two dozen FSA photographers under Stryker's authority made some 270,000 negatives, of which about 80,000 were printed. It was, and is, the most extensive photographic project ever undertaken. The FSA staff included gifted workers such as Walker Evans, Dorothea Lange, and Ben Shahn, and it

THE ANNALS OF IOWA 51 (Fall 1991). (C)The State Historical Society of Iowa, 1991. 
produced a number of enduring images, among them Lange's Migrant Mother and Evans's poignant portraits of Alabama tenant farmers. But more than the photographers, more even than the images, historians have stressed Stryker's role as impresario of the FSA photographic project. This emphasis is signified by the title of F. Jack Hurley's standard history, Portrait of a Decade: Roy Stryker and the Development of Documentary Photography in the Thirties (1972).

JAMES CURTIS'S PURPOSE in Mind's Eye, Mind's Truth is to assert the primacy of visual evidence in understanding the FSA project and its approach to American culture during the depression, and correspondingly to diminish the significance of written documents and thus the centrality of Roy Stryker. He argues that the FSA photographs were not "a painstaking, objective inquiry that disclosed the actuality of rural suffering," but more often were carefully calculated manipulations designed to appeal to the dominant values of American culture. As a general proposition this is more unexceptionable than Curtis apparently believes. In order to give it sufficient argumentative energy he is obliged to create straw men, "modern scholars" who believe that the FSA collection is "a repository of revealed truth." F. Jack Hurley may have subscribed to this naive notion twenty years ago in his pedestrian book on Stryker, and it may have been echoed in Hank O'Neal's tepid discussion accompanying his collection of FSA images of fifteen years ago-the only sources cited for this infirm view-but any contemporary student of photography who professed it would be hooted down. Nowadays no one disputes that the FSA photographs were shaped by a complex set of determinants, including at least the political demands of governmental patronage, the predilections of Stryker and other agency officials, the shared cultural assumptions of the staff, aesthetic considerations, and the political and artistic sensibilities of individual photographers.

If in his general thesis Curtis dresses up conventional wisdom as avant-garde fashion, when he gets down to examining individual photographs he is usually both sensitive and informative. Moreover, his emphasis on the importance of 


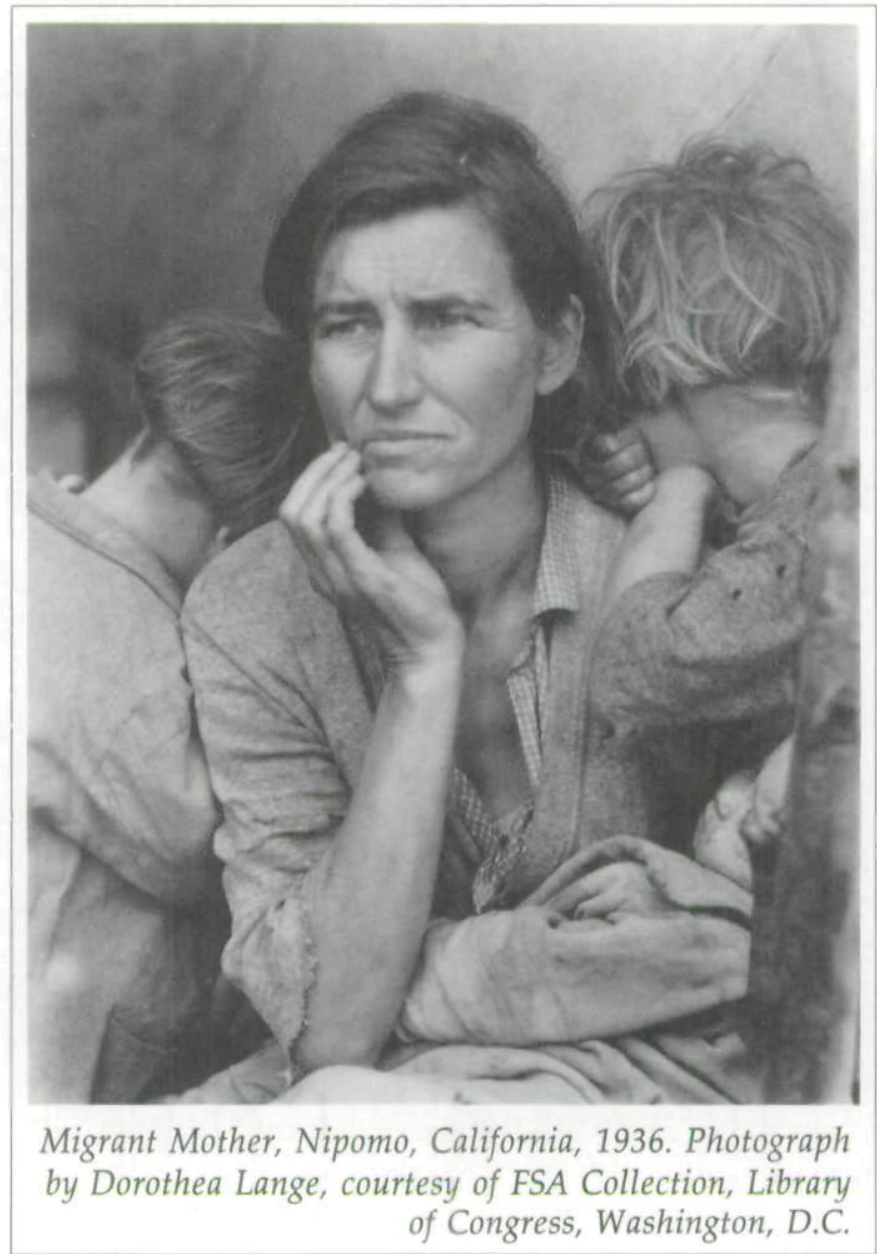

sequences - the entire group of photographs from a shoot, rather than only its best-known image-while not entirely novel is nonetheless uncommon and a useful corrective to the more usual celebrations of single FSA photographic masterpieces, especially inasmuch as the sequences Curtis examines are the very ones out of which some of those individual masterpieces emerged.

Dorothea Lange's Migrant Mother is the FSA's most famous image, perhaps the best-known photograph ever taken. Lange took six photographs of this woman and her family, camped in a frozen California pea field. During the shooting Lange varied the camera's vertical and horizontal format and the lens's dis- 
tance from her subjects, directed the subjects to look toward or away from the camera, included in the images differing combinations of the family's paltry possessions, and varied the number of family members portrayed. None of the first five images (as Curtis plausibly reconstructs the shoot) was entirely satisfactory. The image was too cluttered, or the facial expressions were wrong, or the cultural implications were counter to those Lange wanted the picture to carry. In the first two shots the presence of a teenaged daughter, looking sulky, raised awkward questions about when her mother began bearing children. In the third, of the mother alone nursing her infant, her expression was too defensively cast downward, and a visible pile of dirty clothing carried unwanted implications. In the fourth image, the tent pole obscured part of the infant's head, and a younger daughter posed with her chin awkwardly and unnaturally resting on her mother's shoulder. The fifth shot solved the compositional problems of the fourth, but the mother's impassivity and rigidity kept the viewer at a distance. Only in the final shot did all the elements work, with a brilliant triangular composition, subtle chiaroscuro lighting, powerfully archetypal associations of the vulnerable mother's need to protect her children, irrelevant or disturbing details excised, and the master stroke-drawn from Lange's experience as a studio photographer-of the mother's right hand lightly cupping her cheek, softening the harshness of her expression and signaling her feelings. Curtis is entirely correct to say that "this simple gesture unlocked all the potential that Lange had sensed when she first approached the tent."

By examining Migrant Mother in relation to Lange's entire sequence, Curtis not only underlines the reasons for the extraordinary power of its most affecting photograph but also provides an illuminating conspectus of her working methods and reveals the cultural forces that helped to shape her images. These included not only anxiety about the fate of the family but also assumptions about what size families ought to be and when childbearing ought to begin, a need for reassurance that democratic values would endure the crisis of economic breakdown, and a tension between humanistic and social scientific approaches to the depression's victims. 
Curtis's examination of sequences by Walker Evans, Arthur Rothstein, and Russell Lee are equally illuminating. The pictures of the Alabama tenant farmers Evans contributed to Let Us Now Praise Famous Men were not "literal documents of poverty," but had been carefully orchestrated by the photographer to dramatize the idea that if the tenants needed help they were not themselves helpless, that they had achieved lives of order and dignity in the midst of their poverty. Rothstein's famous and apparently candid photograph of an Oklahoma farmer and his two sons fleeing a dust storm was "an extraordinary symbol of man's struggle against the elements," but it was also carefully posed, not taken in a dust storm at all, and portrayed a farmer determined to stay on his land, not one on the verge of leaving it, as the photograph and its caption implied. Russell Lee's series on Pie Town, New Mexico, was the quintessential expression of Stryker's belief that small towns retained the traditional values and community ties sapped by modernity in larger places, but Lee's study achieved this by acts of legerdemain. Pie Town was located in an area unsuited for farming or grazing and was not largely self-sufficient, as the photographs suggested. American Indians lived nearby and used the town as a major trading center for the piñon nuts they gathered, but since Indians were a potential embarrassment to the virtuous pioneer spirit Stryker and Lee wanted to emphasize, all reference to them in the photographs was suppressed. Lee featured the log cabins in which some of Pie Town's residents lived, although the residents themselves abandoned these dwellings as soon as possible, and he totally ignored the adobe dwellings that were the preferred building style. Curtis's detailed and contextual analyses of such well-known images from the 1930s richly illuminate the ideological commitments and cultural assumptions that animated Lee, Evans, Rothstein, and Lange; less originally, they illustrate the photographers' uses of contrivance in making the images.

Curtis is an informative guide to individual pictures and photographic series, but is less authoritative when he moves away from the images themselves. He identifies William Carlos Williams as a "noted critic," which is rather like calling Edmund Wilson a noted poet. Alfred Stieglitz did not in the 
1920s "turn from" his promotional efforts on behalf of photography to take up his own artistic work, as Curtis suggests, nor did he then adopt a "soft focus" approach; Stieglitz had photographed regularly since the 1890 s, and his major project during the 1920s was "straight" photography, a multi-image portrait of his wife, Georgia O'Keefe. Curtis asserts that Russell Lee's 1936 photograph of an impoverished Christmas dinner in Iowa is published for the first time in Mind's Eye, Mind's Truth; in fact, it appeared in Archibald MacLeish's 1937 Land of the Free, a long poem illustrated by photographs, many of them from the FSA. America in the 1930s, Curtis avers, was "in the early stages of a communications revolution ... [but] was not yet saturated with images." Commercial television had not yet come along, to be sure, but Hollywood made some five thousand films in the decade, Life and Look began publication, tabloid newspapers were at their zenith, and photographs dominated advertising. According to Curtis, the 1930s "had drawn the veil of propriety over the frank sexuality of the Roaring Twenties," a generalization amply contradicted by such phenomena of the 1930s as Mae West's double entendres, Jean Harlow's brassy sexuality, the birth of Esquire magazine with its pneumatic Petty Girls, and the frank eroticism of Hemingway's To Have and Have Not, unmatched in any of his writing from the 1920s.

A more serious problem of historical accuracy occurs in Curtis's discussion of the putative effect of Pare Lorenz's documentary film, The Plow that Broke the Plains, on Arthur Rothstein's Dust Bowl photographs, a major theme in the Rothstein chapter. Fleeing a Dust Storm was "inspired by" The Plow, argues Curtis; "conditioned by exposure to The Plow," Rothstein made his photographs of Oklahoma closely resemble the film's visuals. It is not clear, though, that the similarities Curtis claims were more than fortuitous, because it is uncertain whether Rothstein actually saw the film before he worked in Oklahoma. Lorenz finished a working print of his film in early 1936 and previewed a version of it for President Roosevelt in March; he screened it for the Resettlement Administration staff (as the FSA was then called) on May 1 and premiered it on May 4. Rothstein was already working in the Plains at the beginning 
of April, and perhaps earlier; Curtis cites an April 6 letter from Stryker to Rothstein in the field. Rothstein's photograph, Fleeing a Dust Storm, was shot in April. Rothstein might possibly have seen Lorenz's working print before leaving Washington, but nothing in Curtis's text or footnotes indicates that he did. In fact, Curtis simply ignores the whole problem of chronology. Thus, his claims for the film's influence on Rothstein's photographs are dubious at best.

A similar tendentiousness mars his chapter on Roy Stryker. It is easy to understand why Curtis wished to correct the flaccid hagiography of F. Jack Hurley's book on Stryker, but something more subtle than Curtis's hatchet job is called for. In Curtis's portrait, Stryker encourages toadyism; he is personally insecure, uncomfortable with artistic questions, meanly vindictive, and something of a martinet. He is a "bureaucrat" - a descriptor Curtis uses often and implicitly equates with philistinism. Thus, decisions made by Stryker that might be seen as appropriate, even politically shrewd, are in Curtis's version purblind. When government accountants questioned the photographers' expenses, Stryker responded "by adopting the bureaucratic precept of cost effectiveness, not by appealing to the principles of artistic integrity or freedom of inquiry." Never mind that such appeals would have been futile and irrelevant. We may see the FSA photographers as making art, but that was not the view taken by their patrons, including Rexford Tugwell, the Brain Truster who was responsible for the creation of the photographic unit, not to mention the legislators who appropriated funds for its operation.

This chapter on Stryker is full of conjecture-Stryker "may have," "might have," or "must have" thought something-orother, for which Curtis has no firm evidence-transformed into assertion. Thus Stryker "may well have" gotten the idea for sending photographers into the field from Pare Lorenz; a few sentences later he was "no doubt spurred" by Lorenz's success at getting resources; and finally after an intervening paragraph Stryker was "inspired by Lorenz" to create a cohort of traveling photographers. Such verbal sleights-of-hand are common in Curtis's treatment of Stryker, and they are always used to discredit him. 
Other stratagems employed by Curtis are equally disquieting. Despite his caveat that later interviews with the FSA principals were often unreliable, Curtis ignores his own precept in order to accentuate Dorothea Lange's interview near the end of her life in which she "portrayed Stryker as a bureaucrat who jealously guarded the file, not as a patron whose opinion she respected," even though her letters to Stryker in the 1930s begged him for evaluation of her work. Why privilege recollections of twenty-five years later over contemporaneous documents, unless it is to put Stryker in as unfavorable a light as possible? And why treat as churlish Stryker's decision to "release" Evans to accompany James Agee to Alabama in 1936; isn't it more reasonable to see that assignment as stemming from Stryker's shrewd recognition that the FSA might benefit from a connection with Fortune, Agee's employer, rather than, as Curtis suggests, from Stryker's disgruntlement about Evans's working methods and procedures?

Curtis's acidulous special pleading mars his assessment of Stryker; his general thesis asserting the contrived nature of FSA photographs is a truism; and his use of cultural and historical materials is sometimes weak; but Mind's Eye, Mind's Truth is nevertheless a valuable book for its careful, intelligent analyses of individual photographs and sequences. Also, Temple University Press has designed the book superbly: the scores of photographs are handsomely reproduced, and discussion of each of them is almost always placed on the same or facing page, no easy task with so many images.

About one thing Curtis is indisputably wrong, and so is virtually everyone else who has written about the FSA. Roy Stryker did take photographs, and at least two of them are in the agency's files. Those two are reprinted in Picturing Minnesota, made during Stryker's 1937 junket in the field with Russell Lee, and they indicate that whatever Stryker's talents were, he was not a gifted photographer.

PICTURING MINNESOTA is one of three collections of FSA photographs edited or coedited by Robert L. Reid, organized according to the states in which the images were made: Minnesota, Indiana, and Illinois. Despite their similarity in format- 
oversized and on slick paper, the photographs printed one to a page-the three volumes differ in quality, not because better photographs were made in one or another state but because Reid contextualizes them somewhat more richly in the Illinois volume than in the Minnesota one and much more so than in the Indiana collection. While in the Indiana collection Reid is unable to muster much of a context for the photographs-its introduction wheels out hoary clichés about "classics" and "an important legacy," but provides little else-in the Illinois and Minnesota collections he supplies a modicum of useful information about the states' geographical divisions and their economies and industries, suggests additional sources that could illuminate the images, and speculates about the problems confronted by the photographers in locales such as Chicago's Black Belt. None of the three books, though, rises very far above the level of "album," which is what Reid calls them, a miscellaneous collection of well-made photographs interesting primarily for their nostalgic value.

Several interpretive strategies suggest themselves, however, which could make such collections yield richer insights into the histories and cultures they portray. Reid's headnotes sketch one such approach: an examination of the geographic particularities of a region or subregion and the dynamics of a particular industry or activity. How do Arthur Rothstein's photographs of downstate Illinois coal mining, say, emphasize or de-emphasize certain of its organizational features? Just what view does his photograph of well-dressed union officers suggest about labor organization? Or of white clothes drying against a backdrop of dark coal tenders about the values of the miners' families? Or of a movie theater's prominence on a local main street about the significance of mass culture? A methodical, contextual survey of such a photographic cluster can transform nostalgic images into rich cultural interpretations.

What photographers excluded is often nearly as revealing as what they shot, for such elisions illuminate the photographers' values and those of the agency for which they worked. Labor unrest was endemic in Minnesota, and political radicalism was vigorous, yet Reid's Minnesota collection includes just one shot of a lone striker and none at all of political activities. 
Why did the FSA exclude such important arenas of activity from their conspectus of 1930 s culture?

One of the reasons for the superiority of Reid's Illinois book is its organization of photographs from the South Side of Chicago according to anthropological categories developed in Black Metropolis: A Study of Negro Life in a Northern City (1945). The FSA photographs are particularly informative about family life, religious practices, leisure activities, and other intimate human behaviors often poorly represented in written documents, and thus they can be invaluable to cultural historians. Used more methodically and comprehensively than Reid does, such a screen applied to a state's or region's FSA photographs holds almost limitless possibilities.

The work of understanding and exploiting the FSA photographic file has barely begun. James Curtis's Mind's Eye, Mind's Truth proposes fruitful possibilities based on sequences by individual photographers; Robert L. Reid's collections hint at other approaches drawn from cultural history. What needs to be avoided is the notion that these photographs take "us back in time to a simpler era," as Reid fatuously suggests. The 1930s were as complicated a time as our own, arguably even more so, and the FSA photographs have the potential to visibly reveal that complexity to us. 
Copyright of Annals of Iowa is the property of State of Iowa, by \& through the State Historical Society of Iowa and its content may not be copied or emailed to multiple sites or posted to a listserv without the copyright holder's express written permission. However, users may print, download, or email articles for individual use. 